\title{
Notochordal Plate
}

National Cancer Institute

\section{Source}

National Cancer Institute. Notochordal Plate. NCI Thesaurus. Code C34231.

A thickened epithelial layer of cells, which develops from the notochordal process, that is contiguous with the embryonic endoderm forming a roof to the secondary yolk sac, and giving rise to the notochord. 